\title{
Calcium phosphate submicrometric fibers produced by solution blow spinning
}

\author{
Matheus José Cunha de Oliveira ${ }^{a}$, Roberta Ferreti Bonan ${ }^{b}$, Samara Gomes Campos ${ }^{c}$, Gelmires de \\ Araújo Neves ${ }^{c}$, Romualdo Rodrigues Menezes ${ }^{c}(\mathbb{D}$ \\ anstituto Federal de Educação, Ciência e Tecnologia do Ceará, Av. Dr. Guarani, 317, CEP 62040-730, \\ Sobral, CE, Brasil \\ ${ }^{b}$ Universidade Federal da Paraíba, Joao Pessoa, PB, Brasil \\ ${ }^{c}$ Universidade Federal de Campina Grande, Campina Grande, PB, Brasil
}

Received: November 23, 2018; Revised: March 11, 2019; Accepted: March 21, 2019

\begin{abstract}
The purpose of this work was to produce submicrometric hydroxyapatite (HA) and beta-tricalcium phosphate ( $\beta$-TCP) biphasic fibers by means of solution blow spinning (SBS). This method was chosen due to its lower cost and higher production rate than those of electrospinning, which is normally employed in ceramic fiber production. The fibers thus obtained were characterized by X-ray diffraction (XRD), scanning electron microscopy (SEM), and thermogravimetric analysis (TGA). The in vitro bioactivity and cytotoxicity of the fibers were also investigated. The XRD patterns indicated the formation of biphasic HA/BTCP fibers. SEM analysis revealed an interconnected cylindrical morphology with the presence of beads. Fiber diameters in the submicrometric range varied from 374 to $451 \mathrm{~nm}$. TGA results indicated that organic losses occurred solely below $600^{\circ} \mathrm{C}$. All the fibers were non-cytotoxic, presenting an inhibitory concentration (IC) of $>$ IC50. All the samples successfully formed acicular apatite layers when immersed in SBF, indicating a high potential for in vivo bone bioactivity.
\end{abstract}

Keywords: Calcium phosphate, nanofibers, solution blow spinning.

\section{Introduction}

The most well-known ceramics for bioabsorbable applications are calcium phosphate $(\mathrm{CaP})$. Calcium phosphates are the basic constituents of bones, teeth, animal horns and mammalian tendons. The biomineral phase (one or more types of $\mathrm{CaP}$ ) comprises up to $70 \%$ of bone constituents, the remainder consisting of water and an organic phase, such as collagen ${ }^{1,2}$.

Different calcium phosphates are classified by the $\mathrm{Ca} / \mathrm{P}$ ratio, which ranges from 0.5 to 2.0. Compounds with higher $\mathrm{Ca} / \mathrm{P}$ ratios are less soluble in neutral conditions and have lower degradation rates, while materials with high phosphorus contents are more reactive. Hydroxyapatite, $\mathrm{Ca}_{10}\left(\mathrm{PO}_{4}\right)_{6}(\mathrm{OH})_{2}$, and $\beta$-tricalcium phosphate, $\beta$-TCP, $\mathrm{Ca}_{3}\left(\mathrm{PO}_{4}\right)_{2}$, stand out among these materials. Hydroxyapatite (HA) is an important component and an essential part of bone, and $\beta$-TCP is a common biomaterial used in bone grafts.

HA promotes the formation of a free layer of fibrous tissue containing carbonated apatite on its surface, while $\beta$-TCP presents higher solubility than HA and degrades faster, enhancing the release rate of calcium and phosphorus ions into tissue, thereby favoring new bone growth. This helps the implant attach to living bone, resulting in its early stabilization and its attachment to surrounding tissues ${ }^{3-7}$. For this reason, HA/ $\beta$-TCP ceramics are more effective in bone repair or regeneration than pure HA or pure $\beta$-TCP ${ }^{8}$.

*e-mail: matheus.oliveira@ifce.edu.br
CaP nano-biomaterials support stem cell attachment and proliferation, induce osteogenic differentiation, and enable better bone regeneration than conventional $\mathrm{CaP}$ biomaterials ${ }^{9}$. Studies have therefore focused on the production of nanometric powders of hydroxyapatite and $\mathrm{CaP}$ using several techniques, such as solid state synthesis, hydrothermal ${ }^{10}$, microwaveassisted hydrothermal ${ }^{11}$, sol-gel ${ }^{12}$, and mechanochemical synthesis ${ }^{13}$, among others. However, most of these methods require the use of highly agglomerating powders, which ends up reducing the material's surface area.

On the other hand, CaP nano- and submicrometric fibers are excellent alternatives to circumvent this disadvantage of nanopowders. Nano- and submicrometric fibers have a high specific area, providing most of the advantages and benefits of nanostructured powders without the disadvantage of intense agglomeration. Currently, there is a growing demand for fibers with smaller diameters, i.e., nanometric fibers, in order to increase the flexibility of composite systems and their surface area to volume ratio. The desired fiber morphology depends on the intended application and is influenced by the production method and parameters/conditions of synthesis ${ }^{14}$.

Calcium phosphate fibers can be synthesized by different routes, starting from the sol-gel technique, followed by extrusion, and more often electrospinning. Medeiros 15, 16 developed a method for producing nanofibers, a nonelectrostatic electric field method, by forming a solution cone from an adjustable concentric nozzle. This process, called solution blow spinning (SBS), is a variant of the electrospinning (ES) technique, which is a globally disseminated process 
employed to produce nanometric and micrometric fibers when an electric field is used to overcome the surface tension of a polymer solution, creating a polymer jet. The SBS process precludes disadvantages of ES, such as the need for a potential difference and restrictions about the type of solvent that can be used, while still ensuring high production capacity.

To date, there has been only one report of the SBS technique employed in the production of hydroxyapatite nanofibers that failed to achieve satisfactory fiber quality ${ }^{17}$; moreover, those fibers were not subjected to a bioactivity test. Therefore, the threefold purpose of this work is to produce biphasic HA/ $\beta$-TCP fibers using the SBS technique, to evaluate their structural and morphological behavior as a function of the solids concentration in the precursor solution and the firing temperature of the fibers, and to analyze the cytotoxicity of the fibers and their in vitro bioactivity.

\section{Materials and Methods}

\subsection{Materials}

Triethyl phosphate, TEP (Sigma-Aldrich), and calcium nitrate (Vetec, Brazil) were used as precursors to produce CaP. Polyvinylpyrrolidone, PVP, (average $\mathrm{Mw}=1,300,000$ ) (Sigma-Aldrich) was used as a spinning aid and N,Ndimethylformamide, DMF (Vetec, Brazil) and absolute ethanol (Vetec, Brazil) as solvents.

\subsection{Methods}

Two precursor spinning solutions, samples A1 and A075, were prepared and are described in Table 1. The required quantity of calcium nitrate was homogenized in $8 \mathrm{~mL}$ of absolute ethanol under constant stirring at room temperature $\left(\sim 25^{\circ} \mathrm{C}\right)$ to achieve complete dissolution. TEP was added to each solution, maintaining a $\mathrm{Ca} / \mathrm{P}$ ratio of 1.67 . Then, 700 $\mathrm{mg}$ of PVP (average $\mathrm{Mw}=1,300,000)$ and an aliquot of $2 \mathrm{ml}$ of DMF were also added to each solution. The two solutions were stirred constantly during each step and then for an additional hour, after which they were poured into syringes.

Hybrid fibers (inorganic/PVP fibers) were produced using the SBS apparatus schematized in Figure 1. The system consisted of an injection pump, a compressed air source, a spinning matrix and a collector. The syringe was inserted into the spinning pump and compressed air was used to spin the fibers in a spinning matrix with concentric nozzles. The solution was extruded through the inner nozzle while high pressure air was released through the outer nozzle. The spinning operation was performed inside a heated chamber to help the solvent evaporate at $300^{\circ} \mathrm{C}$. The solution injection rate was set at $0.11 \mathrm{~mL} / \mathrm{min}$ and the air pressure at $0.34 \mathrm{MPa}$. Spun fibers were fired at 900 and $1000^{\circ} \mathrm{C}$, applying a heating rate of $5^{\circ} \mathrm{C} / \mathrm{min}$ and a holding time of $120 \mathrm{~min}$ in air atmosphere. Samples A1 and $\mathrm{A} 075$ fired at $900^{\circ} \mathrm{C}$ were identified as A1900 and $\mathrm{A} 075-900$, while the samples fired at $1000^{\circ} \mathrm{C}$ were identified as A1-1000 and A075-1000.

The cytotoxicity of the fibers was evaluated using peripheral blood mononuclear cells (PBMCs). The cytotoxicity test was conducted in accordance with a protocol approved by the Human Research Ethics Committee (Protocol CAAE 60924816.1.0000.5188) of the Federal University of Paraíba, Brazil. The cytotoxicity test was performed on three healthy, gender-matched patients between 25 and 30 years of age with no history of diseases. The test was performed in triplicate on each patient. The viable cell counts were calculated using the Trypan blue $0.4 \%$ exclusion method (Sigma Aldrich). Cells were suspended at $2 \times 10^{6}$ cells $/ \mathrm{ml}$ in Dulbecco's medium (GIBCO) supplemented with fetal bovine serum (5\%), penicillin (100 IU/ml), streptomycin $(100 \mu \mathrm{g} / \mathrm{ml})$ and $1 \mathrm{mM} \mathrm{N}$-2-hydroxyethylpiperazine-N'-2-ethanesulfonic acid (HEPES). Cytotoxicity was assessed using a LIVE/DEAD Viability/Cytotoxicity kit (Molecular Probes(r)), following the manufacturer's guidelines. Aliquots of $100 \mu \mathrm{l}$ of the PBMCs were plated in 96-well plates and incubated with the ceramic fibers at concentrations of $5 \mathrm{mg} / \mathrm{ml}, 25 \mathrm{mg} / \mathrm{ml}$ and

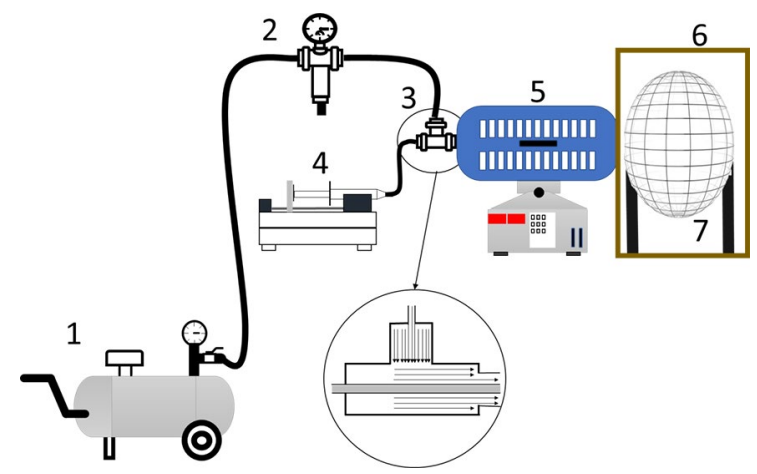

Figure 1. Schematic representation of the Solution Blow Spinning process: 1) Pressurized air 2) Manometer 3) Nozzle 4) Injection pump 5) Tubular furnace 6) Heated chamber 7) Collector.

Table 1. Precursor solutions prepared.

\begin{tabular}{|c|c|c|c|c|c|}
\hline Sample & $\begin{array}{l}\text { Calcium nitrate } \\
\text { (mg) }\end{array}$ & $\begin{array}{l}\text { Tri-ethyl phosphate } \\
\text { (ml) }\end{array}$ & $\begin{array}{c}\text { Sintering } \\
\text { temperature }\left({ }^{\circ} \mathrm{C}\right)\end{array}$ & Inorganic/PVP ratio & $\begin{array}{c}\text { Solids } \\
\text { concentration (\%) }\end{array}$ \\
\hline \multirow{2}{*}{$\mathrm{A} 1$} & \multirow{2}{*}{502} & \multirow{2}{*}{0.218} & 1000 & \multirow{2}{*}{$1: 1$} & \multirow{2}{*}{$14.3 \%$} \\
\hline & & & 900 & & \\
\hline \multirow{2}{*}{ A075 } & \multirow{2}{*}{376.5} & \multirow{2}{*}{0.163} & 1000 & \multirow{2}{*}{$0.75: 1$} & \multirow{2}{*}{$12.5 \%$} \\
\hline & & & 900 & & \\
\hline
\end{tabular}


$50 \mathrm{mg} / \mathrm{ml}$ for 24 hours in a humidity chamber at $37^{\circ} \mathrm{C}$, with $5 \% \mathrm{CO}_{2}$ and humidified atmosphere. Calcein $(1 \mu \mathrm{M})$ and ethidium homodimer $(2 \mu \mathrm{M})$ were added to the wells, and the plates were incubated for $45 \mathrm{~min}$ prior to fluorescence reading. Percentages of viable cells were calculated based on fluorescence readings from control wells containing only samples with or without the markers, $100 \%$ of live or dead cells and labeled with calcein or ethidium homodimer.

In vitro bioactivity was evaluated using simulated body fluid (SBF). The SBF was prepared according to a methodology proposed by Kokubo and Takadama ${ }^{18}$. The samples were immersed in SBF $(2 \mathrm{mg} / \mathrm{ml})$ and kept in an oven at $37^{\circ} \mathrm{C}$ for 7 and 14 days. They were then washed with deionized water and dried in a desiccator at room temperature. The surface of the samples was then characterized by scanning electron microscopy (SEM) to verify the formation or not of an apatite layer.

\subsection{Characterization}

The fibers were characterized by X-ray diffraction (XRD) (Shimadzu, XRD 6000) with $\mathrm{Cu}-\mathrm{K} \alpha$ radiation $(\lambda=1.5418 \AA$ ) in the $2 \theta$ range from 20 to $60^{\circ}$ with $0.02^{\circ}$ increments. The morphology of the fibers was examined by SEM (LEO, SEM 1430). The thermogravimetric behavior of the as-spun fibers was determined (Shimadzu, DTG-60H) from $25^{\circ} \mathrm{C}$ to $1000^{\circ} \mathrm{C}$ in an oxidative atmosphere (synthetic air, $21 \% \mathrm{O}_{2}+$ $\left.79 \% \mathrm{~N}_{2}\right)$ at a heating rate of $5^{\circ} \mathrm{C} / \mathrm{min}$. Fiber diameters $(100$ fibers) were measured using ImageJ software (from the National Institutes of Health, USA).

\section{Results and Discussion}

Figure 2 shows the XRD patterns of the $\mathrm{A} 1$ and $\mathrm{A} 075$ fibers obtained after calcination at 900 and $1000^{\circ} \mathrm{C}$. Note the formation of both hydroxyapatite and the beta-tricalcium phosphate in both fibers at the two temperatures. The peaks of hydroxyapatite phase were determined based on JCPDS file no. 09-0432, and those of the $\beta$-TCP phase were determined based on JCPDS file no. 09-0169. The A1 samples calcined at $1000^{\circ} \mathrm{C}$ and $\mathrm{A} 075$ samples calcined at $900^{\circ} \mathrm{C}$ consisted mainly of hydroxyapatite phase and minor $\beta$-TCP phase, whereas the other samples consisted mainly of $\beta$-TCP phase and minor HA phase.

Calcination temperatures above $700^{\circ} \mathrm{C}$ may cause hydroxyapatite to decompose into $\beta$-TCP, as reported by Ben-Arfa et al. ${ }^{19}$ after they calcined hydroxyapatite obtained by a sol-gel route. However, this was not observed in the A1 composition. These results (Figure 2) indicate that phase formation is influenced not only by the calcination temperature but also by the solids concentration in the precursor solution during the production of $\mathrm{CaP}$ fibers via SBS.

The development of $\beta$-TCP after firing at $900^{\circ} \mathrm{C}$ is in accordance with data reported in the literature ${ }^{20-23}$, which

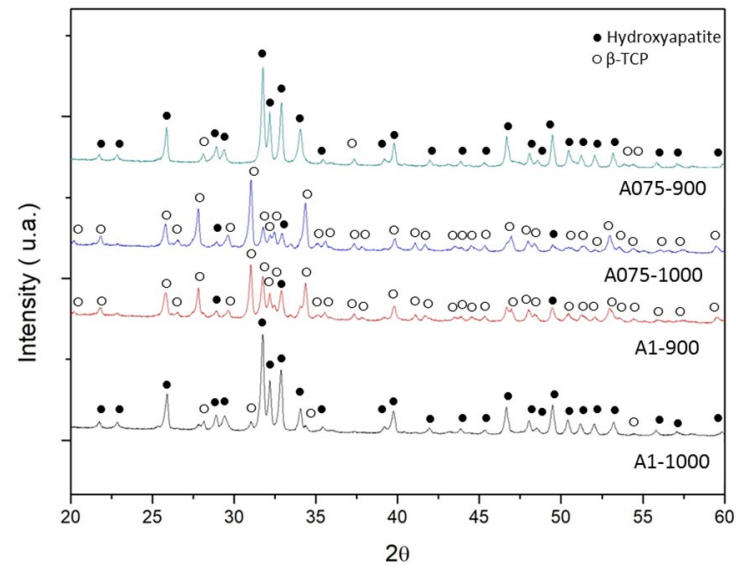

Figure 2. XRD patterns of the obtained fibers.

indicate that HA decomposition may begin to occur starting at $600^{\circ} \mathrm{C}$, but may extend up to $1100^{\circ} \mathrm{C}$, depending on the synthesis route and the calcination atmosphere. We believe that the decomposition of HA into $\beta$-TCP occurred according to the reaction described in the literature ${ }^{23}$. However, the reaction path was altered by the concentration of the polymer in the solution.

$$
\mathrm{Ca}_{10}\left(\mathrm{PO}_{4}\right)_{6}(\mathrm{OH})_{2} \rightarrow 3 \mathrm{Ca}_{3}\left(\mathrm{PO}_{4}\right)_{2}+\mathrm{CaO}+\mathrm{H}_{2} \mathrm{O}
$$

The microstructural evolution of the formulation with the inorganic/organic ratio of $0.75, \mathrm{~A} 075$, occurred as expected, in the case of formulations containing a $\mathrm{Ca} / \mathrm{P}$ ratio of 1.67. Most of the hydroxyapatite but only a low $\beta$-TCP content was formed at $900^{\circ} \mathrm{C}$, probably due to minor compositional segregation in the system. As the temperature increased, the formulation decomposed as described in the literature ${ }^{19}$. However, formulation A1 developed mainly $\beta$-TCP after firing at $900^{\circ} \mathrm{C}$, indicating that the high PVP content may have compromised the homogeneity of $\mathrm{Ca}$ and $\mathrm{P}$ ions in this formulation. Polyvinylpyrrolidone interacts with metal cations and forms unstable complexes ${ }^{24}$. Due to the metallic nature of PVP, calcium ions should interact more strongly with it than with the phosphorous present in TEP. It is known ${ }^{25-28}$ that the carbonyl group of PVP interacts with cations when in solution, as illustrated in Figure 3 for calcium ions. Hence, composition A1 may have contained a large amount of polymer that interacted strongly with the calcium ions, causing a segregation in the reaction, which may have continued after the polymer was calcined, shifting the forming reaction to the production of $\beta$-TCP. The expected equilibrium may have been reached in response to increasing temperature and higher energy for diffusion and reaction, leading to the predominant formation of HA. In this case, if the firing temperature was increased, the HA may have decomposed to form the $\beta$-TCP and amorphous phases of calcium.

The TGA of the as-spun fibers (Figure 4) reveals four stages of mass loss in response to rising temperatures. The 
first stage corresponded to $19 \%$ and was observed within a temperature range of approximately $30^{\circ} \mathrm{C}$ to $220^{\circ} \mathrm{C}$. This mass loss was attributed mainly to the evaporation of retained water and DMF ${ }^{29}$. The second stage, which consisted of a double-step mass loss of $34 \%$ that occurred within a temperature range of $280^{\circ} \mathrm{C}$ to $410^{\circ} \mathrm{C}$, was attributed to the onset of decomposition of the inorganic precursor. PVP degrades basically in two stages: one between $220^{\circ} \mathrm{C}$ and $430^{\circ} \mathrm{C}$, which pertains to the degradation of the PVP side chain, and the other between $450^{\circ} \mathrm{C}$ and $550^{\circ} \mathrm{C}$, resulting from the oxidation and decomposition of residual polymer. The third stage of mass loss, which corresponded to $12 \%$, occurred within a temperature range of 410 to $470^{\circ} \mathrm{C}$ and probably involved TEP decomposition, while the fourth stage was equivalent to $13 \%$ and occurred within a temperature range of 475 to $570^{\circ} \mathrm{C}$, and was attributed to burning of residual carbonaceous PVP and TEP ${ }^{30,31}$. The TGA results indicated that all the organic loss occurred below $600^{\circ} \mathrm{C}$, which is consistent with reports in the literature involving fibers produced using PVP as polymer aid.

Figure 5 depicts SEM micrographs of the spun fibers, showing an interconnected cylindrical morphology in both compositions. All the fibers showed bead formation, but the A075 samples displayed a higher number of beads and defects, indicating that the viscosity of the A1 samples was suitable for the SBS procedure under the processing parameters used here.

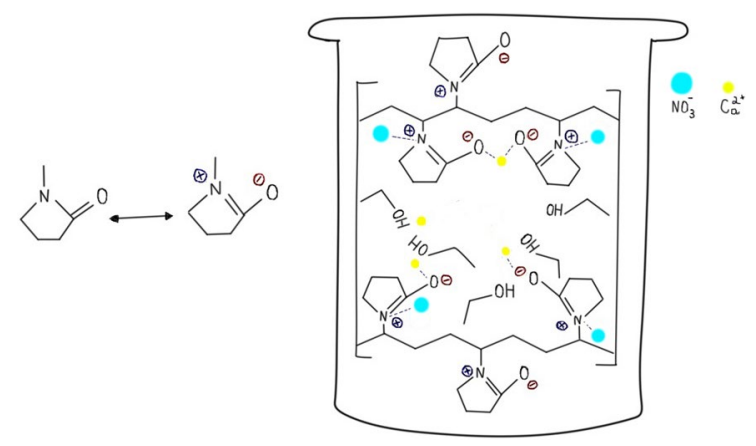

Figure 3. Mechanism of interactions between the PVP and the calcium nitrate ions.

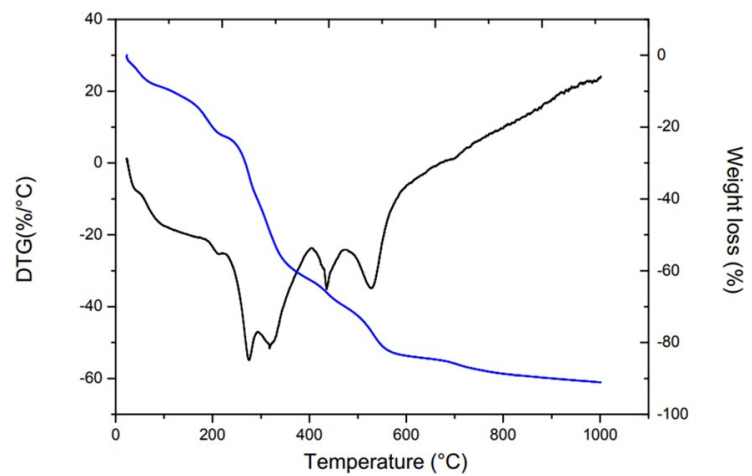

Figure 4. TG analysis of the precursor solution (solids concentration $14.3 \%$ ).
In nano- and submicrometric fiber technology, the main defects produced during spinning and after calcination involve the formation of beads. Micrometric and nanometric polymer particles may appear at low concentrations of polymer in the solution. In this condition, the low entanglement between polymer chains reduces viscosity, and jet beads are formed by a combination of Rayleigh-Taylor instabilities and the action of surface tension of the solution. The fibers between the beads may be excessively stretched during calcination and some of them may break. The ratio of bead diameter to fiber diameter after the electrospinning process is important in the fibrillar structure. Bead discontinuities occur when the ratio of bead to fiber diameters increases ${ }^{20}$. As can be seen in Figure 5, bead formation in SBS was minimized by controlling the solvent ratio in the precursor solution. This is a viable approach comparable to the use of voltage in electrospinning configurations, as previously reported ${ }^{17}$.

Figure 6 illustrates the fiber diameter distribution of the spun fibers, while Table 2 describes the average fiber diameter. The mean diameters of A1-1000 and A1-900 were, respectively, $404 \mathrm{~nm}$ (ranging from 131 to $901 \mathrm{~nm}$ ) and 374 $\mathrm{nm}$ (ranging from 165 to $842 \mathrm{~nm}$ ). The mean diameters of A075-1000 and A075-900 fibers were, respectively, 451 (ranging from 99 to $918 \mathrm{~nm}$ ) and $423 \mathrm{~nm}$ (ranging from 146 to $910 \mathrm{~nm}$ ). An analysis of Figure 6 indicated that all the spun fibers presented a narrow fiber diameter distribution. More than $70 \%$ of the spun fibers showed a length of 600 nm. Sample A1-900 presented a slightly smaller diameter. The fiber diameters produced here by the SBS method were similar to those reported in the literature ${ }^{17,20}$. Note that there was no significant difference between the mean diameter and the diameter distribution of the fibers of A1 and A075 compositions, indicating that is possible to obtain CaP submicrometric fibers via both routes.

Figure 7 illustrates the cell viability of each sample measured after 24 hours in contact with PBMCs. All the tested samples were non-toxic, regardless of their concentration, as indicated by the value of living cells above $50 \%$, i.e., halfmaximal inhibitory concentration, $\mathrm{IC}_{50}{ }^{32}$. At the concentration of 5mg/ml, samples A1-1000 and A075-1000 showed induced cell proliferation. Other samples presented cell viability rates of about $70 \%$, with no significant difference between these values. The test depicted in Figure 7 suggests that the material was highly biocompatible ${ }^{33}$, but the mechanism of cell/fiber interaction will be examined in future studies.

Figure 8 depicts the in vitro bioactivity of fibers immersed in SBF solution for 7 days and 14 days. Note the formation of apatite with acicular morphology on the surface of samples A1-1000, A1-900, and A075-900 after only 7 days of immersion in SBF. The apatite layer on sample A075-1000 was not as evident as that on the other samples in this exposure time. However, after 14 days of exposure, all the samples showed the formation of an apatite layer. Moreover, note the significant increase in the diameter of 

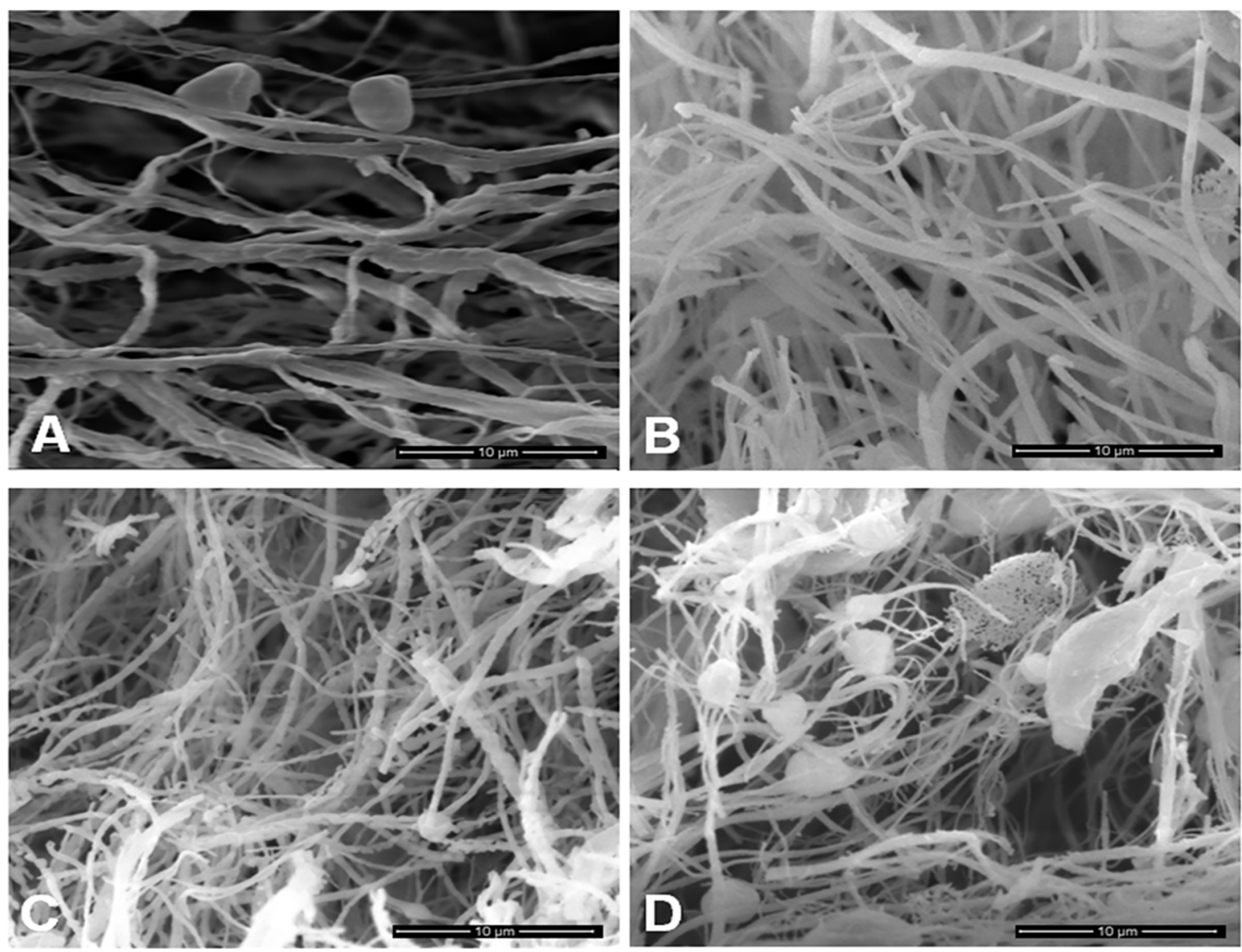

Figure 5. SEM micrographs of the spun fibers A - A1-1000, B - A1-900, C A075-1000, D - A075-900.

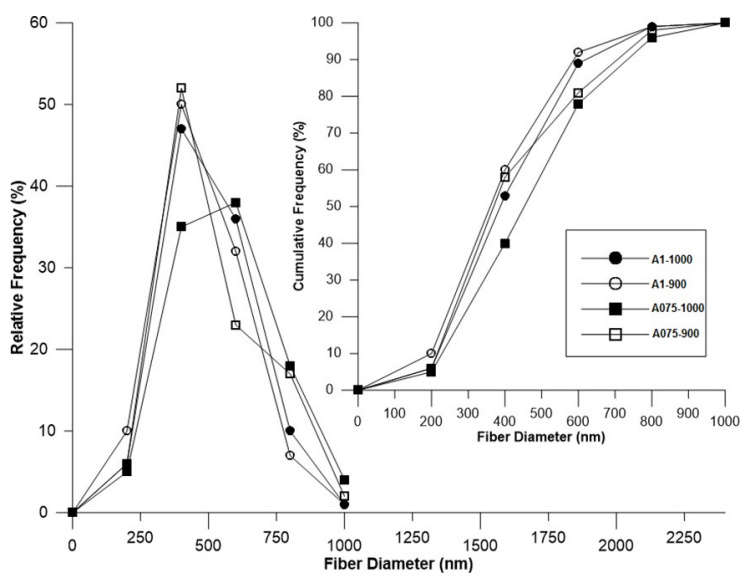

Figure 6. Fibers diameter distribution.

Table 2. Average fiber diameter.

\begin{tabular}{lc}
\hline Sample & Fiber diameter $(\mathrm{nm})$ \\
\hline A1-1000 & 404 \\
A1-900 & 374 \\
A075-1000 & 451 \\
A075-900 & 423 \\
\hline
\end{tabular}

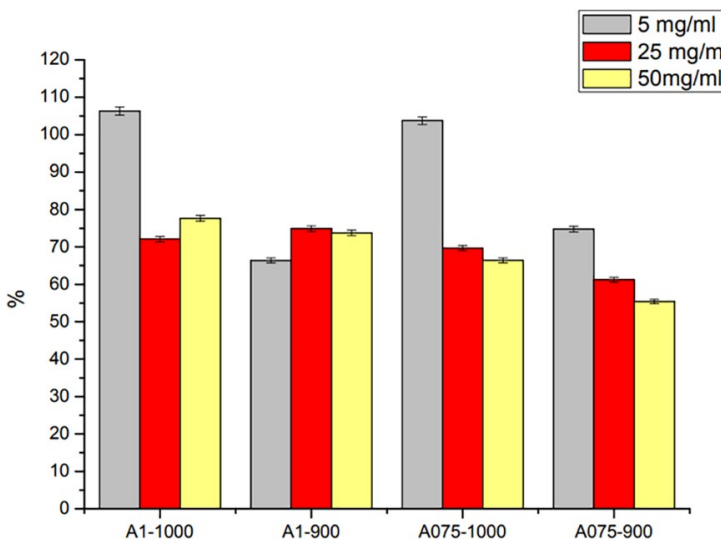

Figure 7. Fluorescence after 24 hours in contact with peripheral blood mononuclear cells (PBMCs).

calcium phosphate fibers after 14 days of exposure to SBF, which was attributed to the increase in apatite layer formation. In vitro testing enables one to predict in vivo bone bioactivity based on the formation of apatite on the material surface after immersion in $\mathrm{SBF}^{20}$, and indicates that all fibers should present in vivo bone bioactivity. The apatite layer is easily formed due to the interaction between the calcium and 

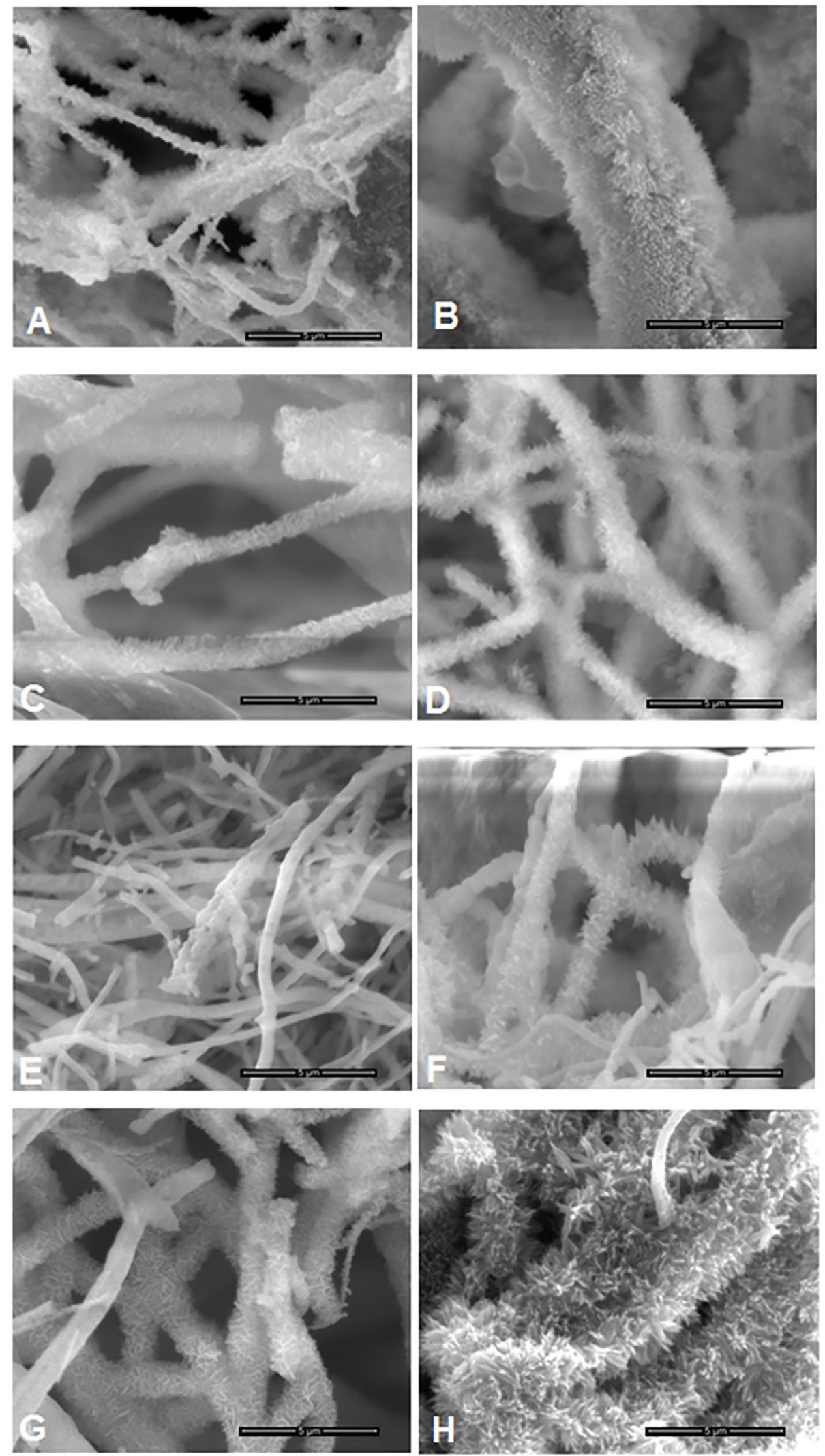

Figure 8. SEM of the fibers after immersion in the SBF: A1-1000 fibers (A) after 7 days (B) after 14 days, A1-900 fibers (C) after 7 days (D) after 14 days, A075-1000 fibers (E) after 7 days (F) after 14 days, A075-900 fibers $(\mathrm{G})$ after 7 days $(\mathrm{H})$ after 14 days. 
phosphate ions in SBF with the calcium phosphate contained in fibers. The surface charge of osteoconductive materials is considered an important factor for the formation of apatite layers in contact with $\mathrm{SBF}^{34}$. Due to its nanofibrous structure, the surface of the fibers allows biomimicry to accommodate and induce the formation of apatite. These nanofibers act as nuclei for the crystallization process ${ }^{33}$. This is confirmed by high surface area nanometric and submicrometric fibers used in place of commonly agglomerated powders ${ }^{12,35-38}$.

\section{Conclusions}

Submicrometric hydroxyapatite and $\beta$-tricalcium phosphate fibers were successfully produced using the solution blow spinning technique. Phase formation was influenced by both temperature and solids concentrations in the precursor solution. TGA results showed that all the organic loss occurred below $600^{\circ} \mathrm{C}$. The average fiber diameter fell within the range of 374 to $451 \mathrm{~nm}$, with a narrow diameter distribution. All the calcium phosphate fibers were non-cytotoxic, as indicated by the half-maximal inhibitory concentration of the three tested concentrations. Moreover, they successfully formed acicular apatite layers when immersed in SBF, suggesting their promising potential for in vivo bone bioactivity.

\section{Acknowledgements}

The authors would like to thank the Brazilian research funding agencies CNPq (National Council for Scientific and Technological Development, under Grant nos. 310932/2015-7 and 483042/2013-7) and CAPES (Federal Agency for the Support and Improvement of Higher Education) for their financial support of this work.

\section{References}

1. Sadat-Shojai M, Khorasani MT, Dinpanah-Khoshdargi E, Jamshidi A. Synthesis methods for nanosized hydroxyapatite with diverse structures. Acta Biomaterialia. 2013;9(8):75917621.

2. Dorozhkin SV. Calcium Orthophosphates in Nature, Biology and Medicine. Materials (Basel). 2009;2(2):399-498.

3. Zairani NAS, Jaafar M, Ahmad N, Razak KA. Fabrication and characterization of porous $\beta$-tricalcium phosphate scaffolds coated with alginate. Ceramics International. 2016;42(4):51415147.

4. Subia B, Kundu J, Kundu SC. Biomaterial Scaffold Fabrication Techniques for Potential Tissue Engineering Applications. In: Eberli D, ed. Tissue Engineering. London: InTechOpen; 2010.

5. Rambhia KJ, Ma PX. Controlled drug release for tissue engineering. Journal of Controlled Release. 2015;219:119-128.

6. Gao C, Deng Y, Feng P, Mao Z, Li P, Yang B, et al. Current progress in bioactive ceramic scaffolds for bone repair and regeneration. International Journal of Molecular Sciences. 2014;15(3):4714-4732.
7. Canillas M, Pena P, de Aza AH, Rodríguez MA. Calcium phosphates for biomedical applications. Boletín de la Sociedad Española de Cerámica y Vidrio. 2017;56(3):91-112.

8. Ramay HR, Zhang M. Biphasic calcium phosphate nanocomposite porous scaffolds for load-bearing bone tissue engineering. Biomaterials. 2004;25(21):5170-5180.

9. Wang P, Zhao L, Liu J, Weir MD, Zhou X, Xu HH. Bone tissue engineering via nanostructured calcium phosphate biomaterials and stem cells. Bone Research. 2014;2:14017.

10. Liu HS, Chin TS, Lai LS, Chiu SY, Chung KH, Chang CS, et al. Hydroxyapatite synthesized by a simplified hydrothermal method. Ceramics International. 1997;23(1):19-25.

11. Hassan MN, Mahmoud MM, El-Fattah AA, Kandil S. Microwaveassisted preparation of Nano-hydroxyapatite for bone substitutes. Ceramics International. 2016;42(3):3725-3744.

12. Agrawal K, Singh G, Puri D, Prakash S. Synthesis and Characterization of Hydroxyapatite Powder by Sol-Gel Method for Biomedical Application. Journal of Minerals \& Materials Characterizations \& Engineering. 2011;10(8):727-734.

13. Nasiri-Tabrizi B, Honarmandi P, Ebrahimi-Kahrizsangi E, PeymanHonarmandi P. Synthesis of nanosize single-crystal hydroxyapatite via mechanochemical method. Materials Letters. 2009;63(5):543-543.

14. Nartetamrongsutt K, Chase GG. The influence of salt and solvent concentrations on electrospun polyvinylpyrrolidone fiber diameters and bead formation. Polymer. 2013;54(8):21662173.

15. Medeiros ES, Glenn GM, Klamczynski AP, Orts WJ, Mattoso LHC. Solution blow spinning: A new method to produce micro and nanofibers from polymer solutions. Journal of Applied Polymer Science. 2009;113(4):2322-2330.

16. Medeiros ES, Glenn GM, Klamczynski AP, Orts WJ, Mattoso LHC, inventors; US Department of Agriculture, assignee. Solution Blow Spinning. United States patent US8641960 B1. 2014 Fev 4.

17. Holopainen J, Ritala M. Rapid production of bioactive hydroxyapatite fibers via electroblowing. Journal of the European Ceramic Society. 2016;36(13):3219-3224.

18. Kokubo T, Takadama H. How useful is SBF in predicting in vivo bone activity? Biomaterials. 2006;27(15):2907-2915.

19. Ben-Arfa BA, Salvado IM, Ferreira JM, Pullar RC. Novel route for rapid sol-gel synthesis of hydroxyapatite, avoiding ageing and using fast drying with a 50 -fold to 200 -fold reduction in process time. Materials Science and Engineering: C. 2017;70(Pt 1):796-804.

20. Dai X, Shivkumar S. Electrospinning of PVA-Calcium Phosphate Sol Precursors for the Production of Fibrous Hydroxyapatite. Journal of the American Ceramic Society. 2007;90(5):14121419 .

21. Lee JH, Kim YJ. Hydroxyapatite nanofibers fabricated through electrospinning and sol-gel process. Ceramics International. 2014;40(2):3361-3369.

22. Franco PQ, João CFC, Silva JC, Borges JP. Electrospun hydroxyapatite fibers from a simple sol-gel system. Materials Letters. 2012;67(1):233-236. 
23. Mouthuy PA, Crossley A, Ye H. Fabrication of calcium phosphate fibres through electrospinning and sintering of hydroxyapatite nanoparticles. Materials Letters. 2013;106:145-150.

24. Liu M, Yan X, Liu H, Yu W. An investigation of the interaction between polyvinylpyrrolidone and metal cations. Reactive and Functional Polymers. 2000;44(1):55-64.

25. Baqer AA, Matori KA, Al-Hada NM, Shaari AH, Kamari $\mathrm{HM}$, Saion E, et al. Synthesis and characterization of binary $(\mathrm{CuO}) 0.6(\mathrm{CeO} 2) 0.4$ nanoparticles via a simple heat treatment method. Results in Physics. 2018;9:471-478.

26. Al-Hada NM, Saion EB, Shaari AH, Kamuradin MA, Flaifel $\mathrm{MH}$, Ahmad SH, et al. A Facile Thermal-Treatment Route to Synthesize $\mathrm{ZnO}$ Nanosheets and Effect of Calcination Temperature. PLoS ONE. 2014;9(8):e103134.

27. Gene SA, Saion EB, Shaari AH, Kamuradeen MA, Al-Hada NM. Fabrication and Characterization of Nanospinel ZnCr2O4 Using Thermal Treatement Method. Advanced Materials Research. 2015;1107:301-307.

28. Abedini A, Saion E, Larki F, Zakaria A, Noroozi M, Soltani N. Room Temperature Radiolytic Synthesized Cu@CuAlO2-A12O3 nanoparticles. International Journal of Molecular Sciences. 2012;13(9):11941-11953

29. Ettarh C, Galwey AK. A kinetic and mechanistic study of the thermal decomposition of calcium nitrate. Thermochimica Acta. 1996;288(1-2):203-219.

30. Lorría-Bastarrachea MI, Herrera-Kao W, Cauich-Rodríguez JV, Cervantes-Uc JM, Vásquez-Torres H, Ávila-Ortega A. ATG/FTIR study on the thermal degradation of poly(vinyl pyrrolidone). Journal of Thermal Analysis and Calorimetry. 2011;104(2):737-742.
31. Bogatyrev VM, Borisenko NV, Pokrovskii VA. Thermal Degradation of Polyvinylpyrrolidone on the Surface of Pyrogenic Silica. Russian Journal of Applied Chemistry. 2001;74(5):839844.

32. International Organization of Standardization (ISO). ISO 10993-5:2009 - Biological evaluation of medical devices - Part 5: Tests for in vitro cytotoxicity. Geneva: ISO; 2009.

33. Pires EG, Bonan RF, Rocha IM, Gonçalves IMF, de Souza JR, Gonzales LHV, et al. Silver-doped 58S bioactive glass as an anti-Leishmania agent. International Journal of Applied Glass Science. 2018;9(1):52-61.

34. Kim HM, Himeno T, Kokubo T, Nakamura T. Process and kinetics of bonelike apatite formation on sintered hydroxyapatite in a simulated body fluid. Biomaterials. 2005;26(21):4366-4373.

35. Faridi-Majidi R, Nezafati N, Pazouki M, Hesaraki S. The effect of synthesis parameters on morphology and diameter of electrospun hydroxyapatite nanofibers. Journal of Australian Ceramic Society. 2017;56(1):225-233.

36. Khandelwal H, Prakash S. Synthesis and Characterization of Hydroxyapatite Powder by Eggshell. Journal of Minerals and Materials Characterization and Engineering. 2016;4(2):119126.

37. Paz A, Guadarrama D, López M, González JE, Brizuela N, Aragón J. A comparative study of hydroxyapatite nanoparticles synthesized by different routes. Química Nova. 2012;35(9):17241727.

38. Wang YZ, Fu Y. Microwave hydrothermal synthesis and characterization of hydroxyapatite nanocrystallites. Materials Letters. 2011;65(23-24):3388-3390. 